研究

$$
\text { メカニカルアロイング Ti-Mo 固溶体とその微細構造 }
$$

$\begin{array}{llll}\text { 岡山大学 大学院 } & \text { 林 } & \text { 雨栄 } & \\ \text { 岡山大学 工学部 } & \text { 飛田 } & \text { 守孝, 榊原 } & \text { 精, 竹元 嘉利 } \\ \text { 岡山大学 理学部 } & \text { 前田 } & \text { 裕宣 } & \\ \text { 岡山理科大学 工学部 } & \text { 助台 栄一 } & \end{array}$

Lim Woo-Yeong, Moritaka Hida, Akira Sakakibara, Yoshito Takemoto, Hironobu Maeda and Ei ichi Sukedai : Mechanically Alloyed Ti-Mo Solid Solution and Its Microstructure. Mixture of $T i$ and Mo powders was mechanically alloyed to obtain $\beta$-type Ti-20mass\%Mo alloy. The mechanism of mechanical alloying(MA) of Ti-20mass\%Mo and microstructure of its product were investigated by $X$-ray diffraction, XAFS and TEM. $x$-ray diffraction profile showed that complete alloying was attained by the $36 \mathrm{ks}$ MA, but incompleteness was revealed by the analysis of XAFS. According to the result of XAFS, $144 \mathrm{ks}-M A$ was needed to accomplish alloying. The radial structural parameters of $j-t h$ shell, $R_{j}, N_{j}$ and $\sigma_{j}$ are obtained by curve fitting method on a two-shell, double Mo-Mo and Mo-Ti pairs. Nearest neighbor bond length( $\left.R_{j}\right)$ decreased with the time of MA. From the observation of TEM, it was revealed that mechanically alloyed particle was composed of small domains with different lattice images in direction, like subgrains. Deformation of the lattice image was also recognized for the MA specimen.

I はじめに

メカニカルアロイング(以下MAと略す)では㸮末状態 の固体をそのまま室温で機械的に加工することによって 合金化あるいはアモルファス化が容易にできることが知 られ大きな関心を集めてきた。枂1970年J.S.Benjamin によって初めて使われた(1)。その後、MAの著しい加工 性が瑟められ色々な合金系に応用されている。しかしMA による合金化の機電と生成した合金の微制檽造について はまだ明かでない。その機桡に対しては局所䖽解に伴う 急冷と固相兹散反忘説(2)がある。そこで我々は今まで

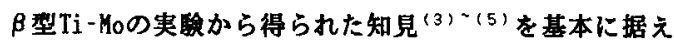
てMAの素過程を明らかにするために本実雅を行った。Ti 合金における $\beta$ 安定化元素であり、Hoと数似の挙娌を示 すVを使ったV基合金(V-Ti）䒚においてはMAによってアモ ルファスにはならないことが埌告されている(8)。ここ では特にMAによる固溶体の生成過程とそれに伴う街細組 嶬变化に着目して得られた䅦果を埌告する。

\section{II 実鹠方法}

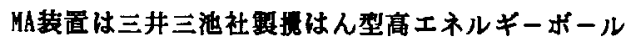
ミル（アトライタMA1D）を用いた。ステンレスタンクに

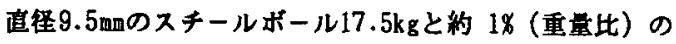

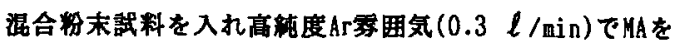
行った。选はんアームの回输速度は300 rpmで、热に よる温度上昇を防ぐために洽却水 $(2 \ell / \mathrm{min})$ を流しなが

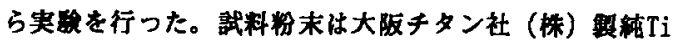

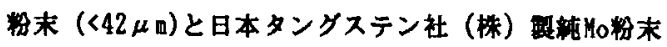

(Received June 7,1990)

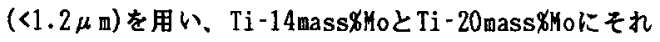
ぞれ配合した。配合された陚料は18ks、36ks、72ks及ひ $144 \mathrm{ks}$ 間ボールミリングを行ってMA処理材（以下MA材と 略す)とした。一方、これらMA材との比較のため、同し

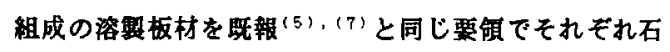
英管中にArガス封入 $\left(10^{-1} \mathrm{~Pa}\right)$ し、1223Kで4.4ks溶体化処 理後、冷水中に急冷処理した。これらの急冷材を油目ヤ スリで粉末化し、㥜材の加工度に近つけるためにメノウ がけによる强加工を模し、澄製物末試料（以下FA枋と略 す)とした。

以上の方法で用意した MA材と FA材についてX線回折、 XAFS (X-ray Absorption Fine Structure) 及びTEM (Transmission Electron Microscope)などを行った。X線回折 剆定の光源は30kV-15nAの単色CuK $\alpha$ を使って2 $\theta=10^{\circ}$ $\sim 110^{\circ}$ の箽囲を $5^{\circ} /$ minで走查した。しかし、線回折 では合金の長籍囲の平均電造しか分からないので原子才 ーダーでの局所檽造を調へるため次のようなXAFS分光を 行つた。高エネルキー研BL-10BにてMoのK吸收端のXAFS を室温で测定し、得られたデータから野径柍造パラメタ (Radial structure paraneter)、すなわち配位数 ( $\mathrm{N}_{i}$; ここて $i=1$ は $M_{0}-M_{0} 、 i=2$ は Mo-Ti 対)，近接原子闌距 離 $\left(\mathrm{R}_{\mathrm{i}}\right)$ 及び Debye-Waller factor $\left(\sigma_{i}\right)$ などを求める ために非線形フィッティング法による解析を行つた。XA FSの解析からはM。まわりの結合に関しての情報は得られ るが実祭にその合金がどのような周期桠造を持っている かを調へるため、明石ビームテクノロジ社鼠超分解能分

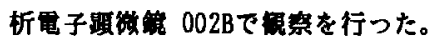




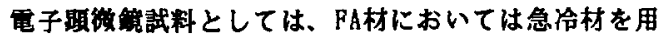
意した。网材にあっては㸮末をアルコール中で分敞させ てできるだけ小さい粒子を選択した。これらの粉末は直 径 $0.2 \mu$ 㕽下のものでよく蚆健行した粒子と考えてよ い。

ここでは得られた結果のうち主にTi-20nassXMoを中心 として報告する。

\section{III 実馱結果及びその考察}

Fig.1はTi-20mass多MoのMA枌のMA処理時間に伴うX線 回折プロファイルの変化とFA材のプロファイルを示した ものである。

まずFig.1(a)の18ksMA材を見ると(110) b0。ピークが2 重になってまだ合金化が不十分であることが分かる。そ れがFig.1(b)の36ks釉材においては両者が接近合併して ピークが 1つになり、ほほ準安定固溶体化が完了したよ うになつた。その祭、高角度倒のピークが低角度㑡のピ ークより移動量が大きいことが琶められた。なお、線 回折では、急冷材で瑟められた $\beta$ 相中の $\omega$ 相が瑟められ なかったのでMAによってい脆化のない高温 $\beta$ 相のみを室 温で作ることができると考えられる。さらにこれ以上72 ks及び144ks MAを進めると加工によってピークが低くブ ロードになることが認められた。

これらの一連の線回折結果から微細組織に何らかの

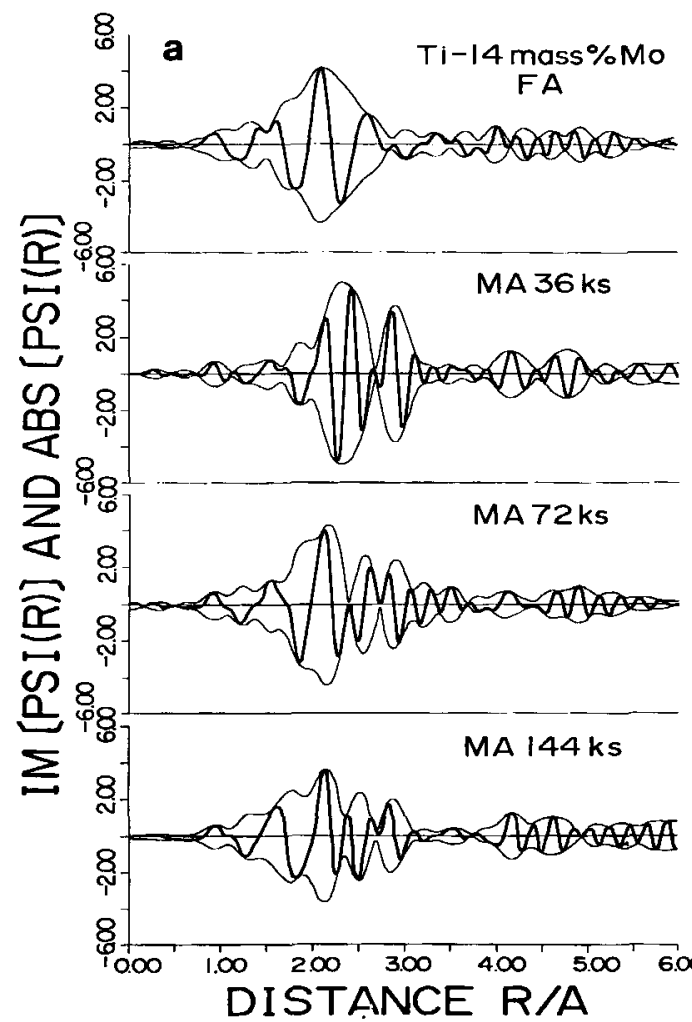

Pig.2 Fourier transformation of the XAFS spectra for the (a)Ti-14mass\%Mo and (b)Ti-20mass\%Mo alloys.

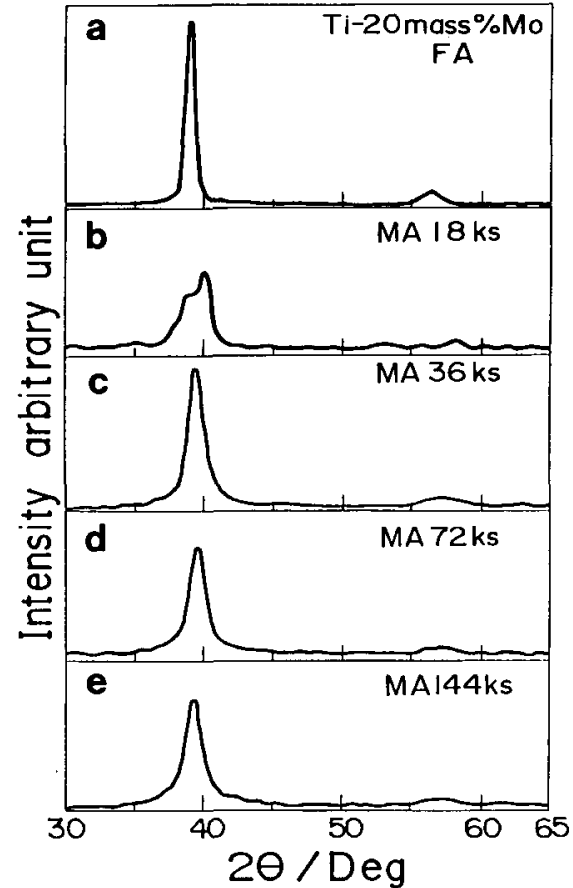

Fig. 1 Comparison of the $X$-ray diffraction profiles (a)melted alloy $(\mathrm{FA})$ and mechanical alloy. (b) $18 \mathrm{ks},(\mathrm{c}) 36 \mathrm{ks}$, (d) $72 \mathrm{ks}$, (e) $144 \mathrm{ks}$.

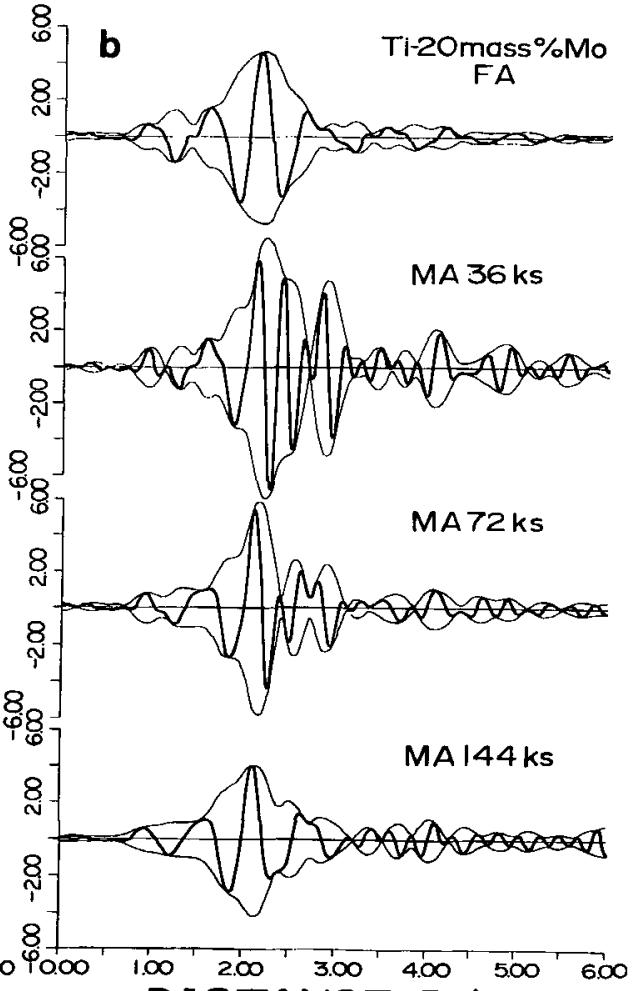

DISTANCE R/A 
Table 1 Structural parameters obtained by non-linear fitting method for the data of EXAFS.

\begin{tabular}{|c|c|c|c|c|c|c|c|c|c|c|c|}
\hline A) $\mathrm{Ti}-14 \mathrm{Mo}$ & $\mathrm{N}$ & $R_{i}(A)$ & $\sigma:(A)$ & $\lambda_{i}(A)$ & $\Delta E_{i}(K E V)$ & B) $\mathrm{Ti}-20 \mathrm{Mo}$ & $\mathrm{N}_{\mathrm{i}}$ & $R_{i}(A)$ & $\sigma_{i}(A)$ & $\lambda_{i}(A)$ & $\Delta E_{i}(K E V)$ \\
\hline$F A$ & & & & & & $F A$ & & & & & \\
\hline 1 Mo-Mo & 1.84 & 2.65 & 0.10 & 7.03 & -0.01 & 1 Mo-Mo & 1.52 & 2.62 & 0.10 & 6.55 & -0.03 \\
\hline $\begin{array}{l}2 \text { Mo-Ti } \\
\text { MA } 36 \mathrm{ks}\end{array}$ & 7.33 & 2.70 & 0.12 & 6.24 & 0.01 & $\begin{array}{l}2 \text { Mo-Ti } \\
\text { MA } 36 \mathrm{ks}\end{array}$ & 7.34 & 2.70 & 0.12 & 6.37 & 0.01 \\
\hline 1 Mo-Ti & 6.87 & 2.71 & 0.09 & & $n$ & 1 Mo-Mo & 3.04 & 2.65 & 0.08 & & $"$ \\
\hline $\begin{array}{l}2 \text { Mo-Ti } \\
\text { MA } 72 \mathrm{ks}\end{array}$ & 40.59 & 2.74 & 0.21 & & $"$ & $\begin{array}{l}2 \text { Mo-Ti } \\
\text { MA } 72 \mathrm{ks}\end{array}$ & 20.72 & 2.73 & 2.20 & & $n$ \\
\hline 1 Mo-Mo & 2.74 & 2.69 & 0.09 & & n & 1 Mo-Mo & 1.59 & 2.64 & 0.08 & & $n$ \\
\hline $\begin{array}{l}2 \text { Mo-Ti } \\
\text { MA } 144 \mathrm{ks}\end{array}$ & 8.97 & 2.73 & 0.13 & & $n$ & $\begin{array}{l}2 \text { Mo-Ti } \\
\text { MA } 144 k s\end{array}$ & 7.50 & 2.66 & 0.15 & & $"$ \\
\hline 1 Mo-Mo & 2.85 & 2.69 & 0.11 & & $n$ & 1 Mo-Mo & 2.39 & 2.62 & 0.11 & & $"$ \\
\hline 2 Mo-Ti & 9.47 & 2.73 & 0.13 & & " & $2 M_{0}-\mathrm{Ti}$ & 7.12 & 2.69 & 0.13 & & $"$ \\
\hline
\end{tabular}

* The distance of Mo-Mo pair obtained from X-ray diffraction data of pure Ho and Ti-20mass\$Mo are $2.72(\mathrm{~A})$ and $2.82(\mathrm{~A})$, respectively.

$\begin{aligned} \Delta R_{i}: M_{0}-M_{0} & = \pm 0.03 \\ M_{0}-T_{i} & = \pm 0.02\end{aligned}$

変化が予想されたので次のXAFSによる局所䨪造の蚞討を 行つた。

Ti-14mass\%MoとTi-20massX特のFA材とMA材のそれそれ のMoK吸収端のXAPSを室温で矵定し、得られたデータの 波数 $\mathrm{k}(1 / \mathrm{A})$ の 3.0から16.0までの籍囲をFourier変换し た結果をFig.2に示す。ます absolute part（外㑡の細 い線）の主ピークを見ると、Ti-14、20mass肺ともに36 ksMA処理によって近接原子間距離がPA材より大きくなっ たことが認められた。Ti-14mass多的においては、MAの進 行にともなって近接原子聞距踓が小さくなるが、144ks まで進めてもFA材のそれより大きい状態で留まっている ことを示している。Ti-20massXHoの場合もほほ同じ便向 が認められたが、144ksMA処理でFA材とほほ同じ值になっ た。次にimaginary part(中㑡の太い線）を見ると、

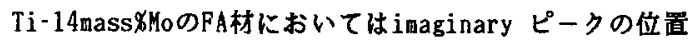
がaboluteのそれと泳致していることが塬められた。 これに対してMA材では144ksまでMAを㻈した場合でもピ ークはいくつかに分睢しており、Moの懪境が不均一であ ることを示している。しかしTi-20mass为作におては。 144ksHA処理によってピークの形がFA材のそれとほほ同じ 棣相を呈している。以上のことより、Ti-20mass如のの場 合、X線回折結果では36ksMAによつて $(110)_{b c c}$ ピークが1 つになり合金化が完了したように認められたが、M。原子 を中心としたXAFSによる局所䀳造を見る限り 144ksMA処 理で合金化が完了したことが諩められた。

ここでstructure parameterすなわち、 $\mathrm{N}_{\mathrm{i}} 、 \mathrm{R}_{\mathrm{i}} 、 \sigma_{\mathrm{i}}$ $\lambda_{i}$ (mean free path of photo electron)及び $\Delta E_{i}$ ( $I$ ネルギー補正值）などを求めるため、Fig.2において1.4 から 2.94(A)の区間を逆Pourier留换し非線形フィッティ
$\Delta R_{i}: M_{0}-M_{0}= \pm 0.03$ Mo-Ti $= \pm 0.01$

ング法 ${ }^{(8)}$ によって解折した結果を次のTable 1 に示す。 この解析では 2 shell model、すなわちMo-TiとMo-Mo 対 モデルを使用した。なお、MA材の入; 及び $\Delta \mathrm{E}$; はFA 材の值に固定した。ここで注目すべき点は Mo-Mol原子間 距䬺であろう。何故なら、Mo原子の搪散はTiのそれより 因踓であることからMoーTi 対の形成は主にMoへのTiの拉

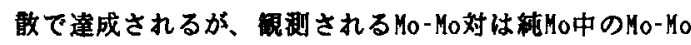
と合金中の Mo-Mo対からなっていると考えられるからで ある。そこで Ti-14mass似のMo-Mo対の距踓を見ると、 36ksMA処理でFA材のそれに比べて大きくなって的が進行 するとともに小さくなった。さらに144ksMh処理後でも FA材のそれより大きい状態でとどまった。Ti-20mass\%o の場合、72ksまではTi-14mass\%Hoと同じ便向を示してい るが、144ksMA材でMo-Mo对の距䭛がFA材とほほ同じにな つた。このことは $144 \mathrm{ks}$ で合金化が完了したことを示し ている。つぎに、Mo-Ti対を見ると、Ti-14mass\&oのMo$\mathrm{Ti}$ 対と同じ偩向が婆められた。

これらのXAPS解析によっては合金化に伴う局所槶造の 装化は分かるが、㹡散混合した原子が合金としてどのよ うな周期性を持っているかは分からないのて奄子䭪微鏡 による組成分析と格子侮の钚察を行つた。

Pig.3(a)は Ti-20massXMoのPA材の格子像を示してい る。 $\beta$ 相の（110)フリンジが広い項城にわたつて規則正 しく並んでいることが罢された。この回折像をみると、 単結晶的なスポットが明寮に周察された。これに対して

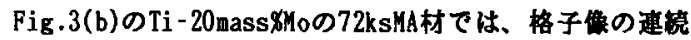
性が狭い項域に限定され、程々の方向の格子像を持つい くつかの面域（直径10nm以下、ソーンと略す）が接合し た槏子を示している。ソーン中の格子鲀にはかなりの雷 

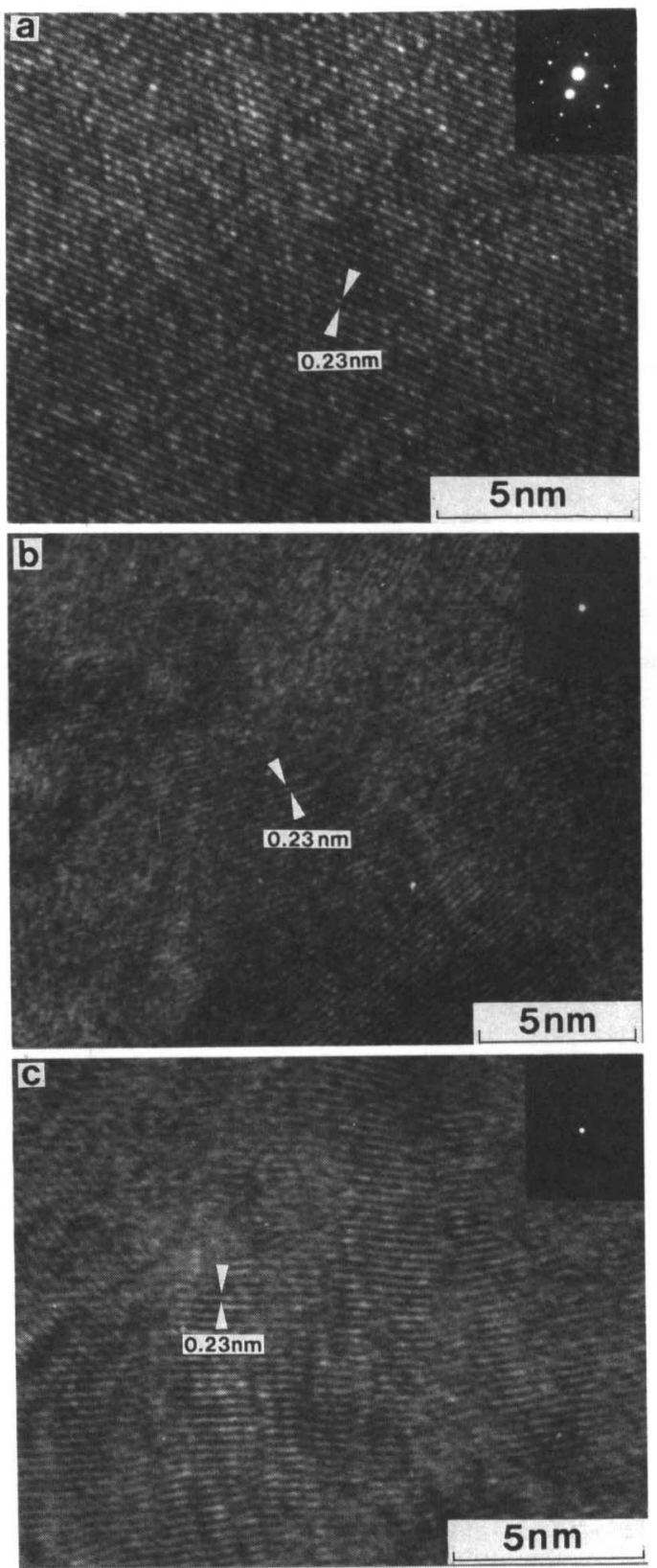

Fig.3 Transmission electron micrographs of (a)melt alloy of Ti-20mass\%Mo(FA), (b)72ks mechanically alloyed(MA) Ti-20mass\$Mo and 36ks MA Ti-14massXMo.

が認められた。格子像が見られない項域はアモルファス のようなコントラストを有している。不均一な回折像

(リング）からも明視野像から得られる構造が亳付けら れる。なお、部分的アモルファスの存在については回折 条件との関係で更に詳䋞に調べる予定である。

Fig.3(c)はTi-14mass\%Moの36ksMA材の明視野像である。 X 線回折及びXAFSの結果からはまだ合金化が不完全であ
るが、試料の選択法を考虑すると、小さい粒子は $\mathrm{Ti}-20$ massXMoの 72ksMA処理材と同じくらい合金化が進んだ格 子像とアモルファス的な領域が認められた。

なお、FA材では急冷 $\omega$ 相の回折図形が明暸に観察され たが、MA材において $\omega$ 相の回折図形は認められなかった。

IV おわりに

以上 Ti-20mass\%oを中心とした一連の実験から得ら れた結果をまとめると、次のようである。

（1）X線回折結果では36ksMA処理によって合金化が完了 したようであるが、XAFSによる局所構造に関する情報で は144ksMA処理でFA材とほぼ同じ状態になった。

（2）MoのK吸収端のXAFS とそのデータの解析によると、 近接原子間距離（R）がMo-Mo、Mo-Ti 対ともにMAによ つて小さくなる傾向が認められた。

（3）MAによる合金の格子像が観察される領域はFA材の それより狭く、かなり歪んでいることが認められた。

(4) MA材の回折図形には $\omega$ 相によるリングは認められ なかつた。

(5) MA材において格子像がみられない領域がアモルフ アス状態を呈しているものかどうか更に詳細に調べる子 定である。

\section{文献}

(1) J.S.Benjamin and T.E.Volin: Metal.Trans. (AIME), $5(1974), 1929$.

(2)R.B.Schwarz and C.C.Koch: Appl.Phys. Lett., 49 (19 86), 146 .

(3)M.Hida, H.Maeda, E.Sukedai, H.Terauchi and N. Kanijo: Proceedings of the International Conference on Martensitic Transformation.1986,637.

(4)M.Hida, E.Sukedai and H.Terauchi: Acta Metall, $36(6),(1988), 1429$.

(5) M.Hida, E.Sukedai and Y.Takemoto: Mater.Trans. JIM, $30(1989), 102$.

(6)E.Hellstern and L.Schultz: Mater.Sci.and Engi., 93(1987), 213.

（7）飛田守孝、助台栄一: 日本金属学会会報、26(1987), 887.

(8) Boon-Keng Teo and P.A.Lee: J. An. Chem. Soc., 101 (1979), 2815. 